\title{
Constituents of Acacia cedilloi and Acacia gaumeri. Revised Structure and Complete NMR Assignments of Resinone
}

Gwendoli G. Pech ${ }^{\mathrm{a}}$, Wendy F. Brito ${ }^{\mathrm{a}}$, Gonzalo J. Mena ${ }^{\mathrm{a}}$ and Leovigildo Quijano ${ }^{\mathrm{b} *}$

a Departamento de Química Orgánica, Facultad de Química, Universidad Autónoma de Yucatán, Calle 41 No. 421, Col. Industrial, 97150 Mérida, Yuc. México

b Instituto de Química, UNAM, Circuito Exterior, Ciudad Universitaria, Coyoacán, 04510, México, D. F., México

* Author for correspondence and reprint requests

Z. Naturforsch. 57c, 773-776 (2002); received April 8, 2002

Acacia, Triterpenes, NMR

The rare lupene derivative named resinone has only been isolated before from Fluorensia resinosa. We now report the isolation of this compound from the bark of the new recently described Acacia cedilloi (Fabaceae), and the revision of its structure to 16 3 -hydroxylup20(29)-en-3-one, based on NMR and MS spectral data. The detailed ${ }^{1} \mathrm{H}$ and ${ }^{13} \mathrm{C}$ NMR assignments of resinone and its acetate achieved by 1D and 2D NMR experiments (including DEPT, COSY, HMQC and HMBC) are reported. In addition, the study of A. cedilloi and A. gaumeri afforded the known related lupenes lupeol and lupenone, the acyclic squalene, the sterols $\beta$-sitosterol, stigmasta-7,22-dien-3 $\beta$-ol (spinasterol) and stigmasta-5,22,25-trien-3 $\beta$ ol (22-dehydroclerosterol) as well as $\alpha$-tocopherol and $\beta$-carotene.

\section{Introduction}

The family Fabaceae the third biggest family of Angiosperms with about 13,000 species, is the predominant family of the flora of the Yucatán Peninsula, where is represented by about 244 species. As part of our search for biologically active compounds of plants from the Yucatán Peninsula, we have undertaken the phytochemical study of $\mathrm{Aca}$ cia cedilloi and $A$. gaumeri two endemic legume species which have not been chemically investigated before. A. cedilloi is a new recently described species which grows in the ecological reserve "El Eden" in the state of Quintana Roo (Rico-Arce, 1994) and A. gaumeri, an important melliferous plant which has also been documented as a medicinal species in the Maya traditional medicine, for the treatment of children's nycturia.

\section{Results and Discussion}

Column chromatography of the hexane and dichloromethane extracts of $A$. cedilloi afforded three triterpenes $16 \beta$-hydroxylup-20(29)-en-3-one identified as resinone (1), lupeol (3) and the acyclic squalene, in addition to common $\mathrm{C}_{12}-\mathrm{C}_{20}$ hydrocarbons, palmitic and oleic acids together with their corresponding methyl esters. While the extracts of A. gaumeri afforded lupeol (3) and lu- penone (4), in addition to sterols $\beta$-sitosterol, stigmasta-7,22-dien-3 $\beta$-ol (spinasterol) and stigmasta5,22,25-trien-3 $\beta$-ol (22-dehydroclerosterol), $\alpha$-tocopherol (vitamin $\mathrm{E}$ ) and $\beta$-carotene.

The triterpene $\mathbf{1}$ was obtained from $A$. cedillo $i$ as a crystalline compound, mp $171-172{ }^{\circ} \mathrm{C}$, which showed low antimicrobial activity against $C$. albicans. The mass spectrum of $\mathbf{1}$ showed a molecular ion peak at $\mathrm{m} / \mathrm{z} 440$ corresponding to a molecular formula $\mathrm{C}_{30} \mathrm{H}_{48} \mathrm{O}_{2}$ as confirmed the ${ }^{13} \mathrm{C}$ NMR and DEPT experiments which indicated the presence of 30 carbon atoms due to seven methyls, ten methylenes, six methines and seven non-protonated carbons. The ${ }^{1} \mathrm{H}$ and ${ }^{13} \mathrm{C} \mathrm{NMR}$ and mass spectral data suggested the presence of a pentacyclic triterpene structure of the lupene type with hydroxyl and carbonyl groups according to the IR absorptions at 3340, 1704 and $1640,880 \mathrm{~cm}^{-1}$. The EI mass spectrum showed characteristic fragment ion peaks at $\mathrm{m} / \mathrm{z} 205,219,234$, which together with the presence of a signal at $\delta 218.1$ for a carbonyl group in the ${ }^{13} \mathrm{C}$ NMR spectrum suggested the presence of the keto group at $\mathrm{C}-3$, as in lupenone (4).

The ${ }^{1} \mathrm{H}$ NMR spectrum of $\mathbf{1}$ displayed signals for typical pentacyclic triterpenoid methyl groups at $\delta 0.81,0.94,1.01,1.02,1.07$, and $1.08\left(\delta_{\mathrm{C}} 11.7\right.$, $16.1,15.9,21.0,26.6$ and 15.8 respectively accord- 


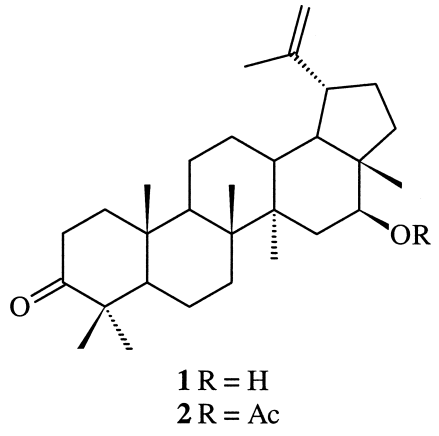

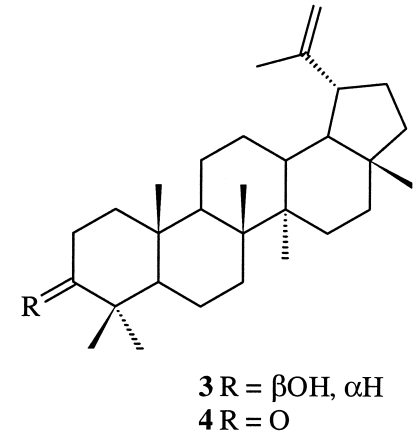

Fig. 1.

ing with the HMQC experiment). The presence of a vinyl methyl broad singlet at $\delta 1.68$ and two vinyl proton signals at $\delta 4.71$ (brd, $J=2.5 \mathrm{~Hz}$ ) and 4.60 (dq, $J=2.5,1.5 \mathrm{~Hz}$ ) with ${ }^{13} \mathrm{C}$ absorptions at $\delta 19.3$, 149.9 and 109.8 are characteristic of the isopropenyl group of triterpenes of the lupene type. The ${ }^{1} \mathrm{H}$ NMR spectrum also showed a doublet of doublets at $\delta 3.61(J=11.0,4.5 \mathrm{~Hz})$ due to a hydroxymethine group $\left(\delta_{C} 76.9\right)$. The multiplicity and the coupling constant values indicated an axial orientation of the proton and limited the location of the hydroxyl group to C-7, C-15 or C-16. Positions C-7 and C-15 can be excluded by comparison of the ${ }^{13} \mathrm{C}$ NMR data of $\mathbf{1}$ with those of the known 7 $\beta$-hydroxylup-20(29)-en-3-one (Anaya et al., 1989), and lup-20(29)-en-3 $\beta, 15 \alpha$-diol (Tanaka et al., 1993). On the other hand, comparison of the ${ }^{13} \mathrm{C}$ NMR data of compound 1 with those of lupenone (4) and those reported for lup-20(29)en-3 $\beta, 16 \beta$-diol were in good agreement with the presence of the keto group at C-3 and the hydroxyl group at C-16 (Wenkert et al., 1978). The HMBC experiment confirmed the presence of the carbonyl group at C-3 and the hydroxyl group at C-16. Long-range couplings were observed between the carbonyl signal at $\delta 218.1$ and the gemdimethyl proton signals at $\delta 1.08$ and 1.03 (C-23 and C-24). These two methyl signals were in turn coupled with a quaternary carbon at $\delta 47.3$ and a methine group at $\delta 54.9$ allowing the assignment of these signals to $\mathrm{C}-4$ and $\mathrm{C}-5$ respectively. Further coupling of the methine carbon at $\delta 54.9$ (C-5) with the methyl signal at $\delta 0.93$ indicated that this signal is due to the methyl group at $\mathrm{C}-10(\mathrm{H}-25)$. The long-range coupling between the methine signal at $\delta 76.9$ and the methyl signal at $\delta 0.81(\mathrm{H}-28)$, indicated that the secondary alcohol must be at
C-16. The $\beta$-orientation of the hydroxyl group was indicated by the coupling constants of the H-16 proton. Therefore the structure of compound $\mathbf{1}$, was determined as 16 $\beta$-hydroxylup-20(29)-ene-3one. Acetylation of $\mathbf{1}$, gave the corresponding acetate 2. All spectral NMR data of acetate $\mathbf{2}$ were in good agreement and confirmed the proposed structure $\mathbf{1}$.

A search of the literature indicated that structure 1 must correspond to resinone, a rare pentacyclic triterpene isolated from Flourensia resinosa (Asteraceae) (Rodriguez-Hahn and Rodriguez, 1972). The structure of resinone was established as the $12 \beta$-hydroxy derivative of lupenone (4) by chemical correlation with the oxidation product of thurberin (or calenduladiol) a lupene diol independently isolated from Lemaireocereus thurberi and Calendula officinalis, whose structure had been erroneously established as lupen-20(29)-

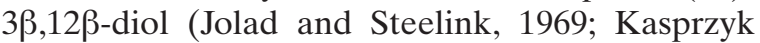
and Pyrek, 1968). Later on, the identity of thurberine and calenduladiol, was recognized and the structure revised to lupen-20(29)-3 $\beta, 16 \beta$-diol keeping the name calenduladiol (Kasprzyk et al., 1970; Protiva et al., 1977). Moreover, the revised structure of thurberin and calenduladiol corresponds with that of beyeriadiol, a compound isolated before from Beyeria leschenaultii (Baddeley et al., 1964). Therefore, the structure of resinone must be revised to 16 $\beta$-hydroxylup-20(29)-en-3one (1) and the names thurberin and calenduladiol eliminated from the literature. This is the second report on the natural occurrence of compound $\mathbf{1}$.

The known lupeol (3) and lupenone (4), were identified by comparison of their NMR and MS spectral data. ${ }^{1} \mathrm{H}$ and ${ }^{13} \mathrm{C}$ NMR assignments based on $1 \mathrm{D}$ and $2 \mathrm{D}$ experiments, including DEPT, 
Table I. ${ }^{1} \mathrm{H}$ and ${ }^{13} \mathrm{C}$ NMR spectral data for 16ß-hydroxylup-20(29)-en-3-one (1) (500 MHz, $\left.125 \mathrm{MHz}\right)$ and its acetate (2) $(400 \mathrm{MHz}, 100 \mathrm{MHz})$, in $\mathrm{CDCl}_{3}$.

\begin{tabular}{|c|c|c|c|c|c|c|}
\hline & $\begin{array}{l}\delta_{C} \\
(\mathbf{1})\end{array}$ & $\begin{array}{l}\delta_{\mathrm{H}} \\
(\mathbf{1})\end{array}$ & $\underset{(\mathbf{1})}{\mathrm{HMBC}}$ & $\begin{array}{l}\delta_{C} \\
(2)\end{array}$ & $\begin{array}{l}\delta_{H} \\
(2)\end{array}$ & $\underset{(\mathbf{2})}{\mathrm{HMBC}}$ \\
\hline $1 \mathrm{a}$ & $39.6 \mathrm{t}$ & $1.38 \mathrm{~m}^{*}$ & H-25 & 39.6 & 1.39 & H-2a, 2b, 25 \\
\hline $1 b$ & & 1.90 ddd $(13.0,7.5,4.5)$ & & & 1.89 & \\
\hline $2 \mathrm{a}$ & $34.1 \mathrm{t}$ & 2.40 ddd $(16.0,8.5,4.5)$ & & 34.1 & 2.42 & $\mathrm{H}-1 \mathrm{~b}$ \\
\hline $2 \mathrm{~b}$ & & $2.49 \mathrm{ddd}(16.0,9.5,7.5)$ & & & 2.48 & \\
\hline 3 & $218.1 \mathrm{~s}$ & --- & $\mathrm{H}-23,24,2 \mathrm{~b}$ & 218.1 & --- & $\mathrm{H}-1,2,23,24$ \\
\hline 4 & $47.3 \mathrm{~s}$ & --- & $\mathrm{H}-23,24$ & 47.3 & --- & $\mathrm{H}-23,24$ \\
\hline 5 & $54.9 \mathrm{~d}$ & $1.30 \mathrm{~m}^{*}$ & $\mathrm{H}-23,24,25$ & 54.7 & 1.32 & H-23, 24, 25 \\
\hline $6 a, b$ & $19.6 \mathrm{t}$ & $1.48 \mathrm{~m} *(2 \mathrm{H})$ & & 19.6 & 1.48 & \\
\hline $7 a, b$ & $33.5 \mathrm{t}$ & $1.43 \mathrm{~m} *(2 \mathrm{H})$ & H-26 & 33.5 & 1.42 & H-26 \\
\hline 8 & $40.9 \mathrm{~s}$ & --- & H-26, 27 & 40.9 & --- & H-26, 27 \\
\hline 9 & $49.4 \mathrm{~d}$ & $1.36 \mathrm{~m} *$ & H-25, 26 & 49.3 & 1.37 & $\mathrm{H}-25,26$ \\
\hline 10 & $36.8 \mathrm{~s}$ & --- & H-25 & 36.8 & --- & H-1b, 2a, 25 \\
\hline $11 \mathrm{a}$ & $21.4 \mathrm{t}$ & $1.26 \mathrm{~m} *$ & & 21.4 & 1.25 & \\
\hline $11 \mathrm{~b}$ & & $1.42 \mathrm{~m}^{*}$ & & & 1.45 & \\
\hline $12 \mathrm{a}$ & $24.8 \mathrm{t}$ & $1.04 \mathrm{~m} *$ & & 24.7 & 1.06 & \\
\hline $12 b$ & & 1.70 brd $(15.0)$ & & & 1.70 & \\
\hline 13 & $37.4 \mathrm{~d}$ & $1.64 \mathrm{~m}^{*}$ & H-27 & 37.5 & 1.69 & H-27 \\
\hline 14 & $44.1 \mathrm{~s}$ & --- & H-26, 27 & 44.2 & --- & H-26, 27 \\
\hline $15 \mathrm{a}$ & $36.8 \mathrm{t}$ & $1.30 \mathrm{~m}^{*}$ & $\mathrm{H}-27$ & 33.5 & 1.32 & $\mathrm{H}-16,27$ \\
\hline $15 b$ & & $1.57 \mathrm{t}(12.5)$ & & & 1.63 & \\
\hline 16 & $76.9 \mathrm{~d}$ & $3.62 \mathrm{dd}(11.0,4.5)$ & $\mathrm{H}-15,28$ & 79.0 & 4.87 & $\begin{array}{l}\mathrm{H}-15 \mathrm{a}, \quad 15 \mathrm{~b}, \\
28\end{array}$ \\
\hline 17 & $48.6 \mathrm{~s}$ & --- & H-28 & 47.3 & --- & H-16 \\
\hline 18 & $47.7 \mathrm{~d}$ & $1.40 \mathrm{~m} *$ & H-28 & 47.7 & 1.51 & $\mathrm{H}-16,28$ \\
\hline 19 & $47.6 \mathrm{~d}$ & $2.50 \operatorname{td}(11.5,5.5)$ & H-30, 29a, 29b & 47.5 & 2.50 & H-29b, 30 \\
\hline 20 & $149.9 \mathrm{~s}$ & --- & $\mathrm{H}-30$ & 149.8 & --- & H-19, 30 \\
\hline $21 \mathrm{a}$ & $29.9 \mathrm{t}$ & 1.40 ddd $(12.0,8.5,1.5)$ & & 29.7 & 1.52 & H-19 \\
\hline $21 b$ & & $1.98 \mathrm{~m}$ & & & 1.95 & \\
\hline $22 \mathrm{a}$ & $37.7 \mathrm{t}$ & $1.28 \mathrm{~m} *$ & H-28 & 37.6 & 1.33 & H-16, 28 \\
\hline $22 b$ & & $1.65 \mathrm{~m}^{*}$ & & & 1.69 & \\
\hline 23 & $26.6 \mathrm{q}$ & $1.07 \mathrm{~s}$ & H-24 & 26.7 & 1.06 & H-24 \\
\hline 24 & $21.0 \mathrm{q}$ & $1.02 \mathrm{~s}$ & H-23 & 21.0 & 1.02 & $\mathrm{H}-23$ \\
\hline 25 & $16.1 \mathrm{q}$ & $0.94 \mathrm{~s}$ & & 16.0 & 0.95 & \\
\hline 26 & $15.8 \mathrm{q}$ & $1.08 \mathrm{~s}$ & & 15.8 & 1.07 & \\
\hline 27 & $15.9 \mathrm{q}$ & $1.01 \mathrm{~s}$ & $\mathrm{H}-15$ & 15.9 & 1.06 & \\
\hline 28 & $11.7 \mathrm{q}$ & $0.81 \mathrm{~s}$ & H-18, 22 & 12.7 & 0.86 & H-16 \\
\hline $29 \mathrm{a}$ & $109.9^{\mathrm{t}}$ & $4.60 \mathrm{dq}(2.0,1.5)$ & $\mathrm{H}-30$ & 110.0 & 4.60 & H-19, 30 \\
\hline $29 b$ & & 4.71 brd $(2.5)$ & & & 4.71 & \\
\hline 30 & $19.3 \mathrm{q}$ & $1.68 \mathrm{brs}$ & H-29a, 29b & 19.2 & 1.68 & H-29a, 29b \\
\hline \multirow[t]{2}{*}{$\mathrm{AcO}-$} & & & & 21.4 & 2.03 & \\
\hline & & & & 170.8 & & H-16 \\
\hline
\end{tabular}

* Assignments and chemical shifts of overlapped ${ }^{1} \mathrm{H}$ multiplets are based on COSY NOESY and HMQC experiments. a,b refers to relative configuration of protons.

COSY, NOESY, HMQC and HMBC are in good agreement with the recently reported data (Burns et al., 2000).

\section{Experimental}

\section{General}

Melting points were determined on a Fischer Jones type apparatus and are uncorrected. Optical rotations were measured in $\mathrm{CHCl}_{3}$ solutions on a
Jasco DIP 360 polarimeter. IR spectra were recorded on $\mathrm{KBr}$ disks on a Nicolet Magna Fourier transform IR spectrometer 550. EIMS were obtained on a Hewlett-Packard 5892 mass spectrometer using a Hewlett-Packard 5970 series II gas chromatograph as injection system. NMR spectra were recorded on a Varian Unity Plus 500 and Bruker Advance 400 spectrometers in $\mathrm{CDCl}_{3}$ solutions with TMS as internal standard, chemical shifts are recorded in $\delta$ values. 


\section{Plant material}

Acacia cedilloi (L) Rico was collected at the "El Eden" ecological reserve located $21^{\circ} 3^{\prime} \mathrm{N}$, $87^{\circ} 11^{\prime}$ W of Cancún Q. R. (México) in July 1996. A. gaumeri Blake, was collected at the $8 \mathrm{~km}$ on the road Kanasin-Acancéh in the state of Yucatán (México) in January 1999. Voucher specimens have been deposited at the herbarium Alfredo Barrera Marin, Universidad Autónoma de Yucatán, Mérida, Yuc., México.

\section{Extraction and isolation}

Dried and ground bark (664 g) and leaves (380 g) of $A$. cedilloi were extracted separately at room temperature by percolation with hexane and $\mathrm{CH}_{2} \mathrm{Cl}_{2}$ to give $2.7 \mathrm{~g}$ and $26.0 \mathrm{~g}$ of residue respectively. The bark $(400 \mathrm{~g})$ and leaves $(450 \mathrm{~g})$ of $A$. gaumeri were extracted in the same way giving $9.0 \mathrm{~g}$ and $10.0 \mathrm{~g}$ of residue, respectively. Column chromatography of the bark residue of $A$. cedilloi, on silica gel using hexane and hexane- $\mathrm{CH}_{2} \mathrm{Cl}_{2}$ mixtures of increasing polarity. GC-MS of the low polar fractions indicated the presence of squalene, mixtures of common $\mathrm{C}_{12}-\mathrm{C}_{20}$ hydrocarbons, palmitic and oleic acid together with their corresponding methyl esters. Fractions eluted with hexane- $\mathrm{CH}_{2} \mathrm{Cl}_{2}$ 7:3 v/v afforded the crystalline 16 $\beta$-hydroxylup-20(29)-en-3-one (1). From the chromatography of the leaf residue, lupeol (3) and $\beta$-sitosterol were obtained from fractions eluted with hexane-EtOAc 9:1 v/v and hexane-EtOAc 7:3 respectively. The $\mathrm{CH}_{2} \mathrm{Cl}_{2}$ extract of the bark of $A$. gaumeri was fractionated by column chromatography on silica gel using mixtures of hexane-EtOAc (9:1, 8:2, 6:4 v/v). Lupenone (4) and lupeol (3) were obtained from fractions eluted with hexaneEtOAc 9:1. Fractions eluted with hexane-EtOAc $8: 2$ gave a sterol identified as stigmasta-7,22-diene$3 \beta$-ol (spinasterol). Column chromatography over silica gel of the leaf extract using mixtures of hexane-EtOAc afforded $\alpha$-tocopherol (vitamin E), $\beta$-carotene in the low polar fractions and stigmasta-5,22,25-triene-3 $\beta$-ol (22-dehydroclerosterol) in fractions eluted with hexane-EtOAc 8:2.

\section{6ß-hydroxylup-20(29)-en-3-one (1)}

Colorless crystals, mp $171-172^{\circ},[\alpha]_{\mathrm{D}}^{25}+43.8^{\circ}$ (c $1.6 \mathrm{mg} / \mathrm{ml}, \mathrm{CHCl}_{3}$ ); IR (KBr) $v_{\max } 3341,3072$, 1704, $805 \mathrm{~cm}^{-1}$; EIMS m/z 440 [M]+ (100), 422 (69), 407 (28), 358 (53), 313 (22), 234 (17), 219 (19), 205 (51), 121 (35), 108 (71), 95 (52), 81 (59), 68 (83), 55 (68), 43 (49); ${ }^{1} \mathrm{H}$ and ${ }^{13} \mathrm{C}$ NMR (see Table I).

\section{Acknowledgements}

The authors wish to thank Isabel Chávez-Uribe for technical assistance with the high-resolution NMR experiments and Jose Marrufo-Gómez for GC-MS technical assistance.
Anaya J., Caballero M. C., Grande M., Navarro J. J., Tapia I and Almeida J. F. (1989), A lupeol derivative from Salvia pratensis. Phytochemistry 28, 2206-2208.

Baddeley G. V., Bealing, A. J., Jefferies P. R. and Retallack R. W. (1964), The chemistry of Euphorbiaceae VI. A triterpene from Beyeria leschenaulth. Aust. J. Chem. 17, 908-914.

Burns D., Reynolds W. F., Buchanan G., Reese P. B. and Enriquez R. G. (2000), Assignment of ${ }^{1} \mathrm{H}$ and ${ }^{13} \mathrm{C}$ spectra and investigation of hindered side-chain rotation in lupeol derivatives. Mag. Res. Chem. 38, 488493.

Jolad S. D. and Steelink C. (1969), Thurberin, a new pentacyclic triterpene from organ pipe cactus. J. Org. Chem. 34, 1367-1369.

Kasprzyk Z. and Pyrek J. (1968), Triterpenic alcohols of Calendula officinalis. Phytochemistry 7, 1631-1639.

Kasprzyk Z., Pyrek J., Jolad S. D. and Steelink C. (1970), The identity of calenduladiol and thurberin: A lupe- nediol found in marigold flowers and organ pipe cactus. Phytochemistry 9, 2065-2066.

Protiva J., Turecek F. and Vystrcil A. (1977), Revised structure of thurberine. Synthesis of 3,12-lupanedione. Collect. Czech. Chem. C. 42, 140-150.

Rico-Arce M. L. (1994), Nueva especie mirmecofila de Acacia (Leguminoseae) de la Península de Yucatán, México. Acta Botánica Mexicana 26, 7-10.

Rodriguez-Hahn L. and Rodriguez J. (1973), Resinona, un nuevo triterpeno aislado de Fluorensia resinosa. Rev. Latinoam. Quim. 3, 148-153.

Tanaka R., Mazuda K. and Matsunaga S. (1993), Lup20(29)-en-3 $\beta, 15 \alpha$-diol and ocotillol II from the stem bark of Phyllanthus flexuosus. Phytochemistry 32, $472-474$.

Wenkert E., Baddeley G. V., Burfitt I. R. and Moreno L. N. (1978), Carbon-13 nuclear magnetic resonance spectroscopy of naturally-occurring substances. Org. Mag Res. 11, 337-343. 